\title{
DESIGNING OF LEARNING ACTIVITY FOR EXPLICATING NATURE OF SCIENCE
}

\author{
Anggiyani Ratnaningtyas Eka Nugraheni and Chokchai Yuenyong \\ Faculty of Education, Khon Kaen University, Thailand \\ email: anggiyaniratnaningtyas@kkumail.com
}

\begin{abstract}
This study was aimed at clarifying the learning activities for explicit Nature of Science (NOS) which provide through context based STS (Science, Technology, Society) learning approach. The study followed the 4-D procedure but in this article only was presented up to the third step. These steps included define, design, and develop. The data were gathered through expert judgment by chemistry educator for product revision. The views of the chemistry teacher were explored through a closed-questionnaire that was analyzed by percentage. One of learning activity plan have arranged. The learning activity with context based STS approach consists of 5 stages including identification of social issues/history, identification of potential solution, need for knowledge, decision-making, and socialization and completion decision stage. Chemistry teachers' view toward the feasibility of learning activity plan was good. The learning activity was developed with topic a history of the Father of Modern Chemistry for grade 10th. The findings show thatt his learning activity is able to help teacher for teaching NOS in classroom and foster students' NOS through a historical story.
\end{abstract}

Keywords: basic law of chemistry, nature of science, learning activity

\section{INTRODUCTION}

One of the $21^{\text {st }}$ skills demand is to have scientific literacy. The scientific literacy is commonly defined as the ability to critically analyze and evaluate the information of the scientific ideas and concepts required for personal decisionmaking in the daily life situations (Jarman \& McClune, 2007; OECD, 2015; Shwartz, Ben-Zvi, \& Hofstein, 2006; Cigdemoglu, Arslan, \& Cam, 2017). However, the study conducted by the Programme for International Students Assessment (PISA) shows that Indonesian students' scientific literacy is very low compared to other countries. In 2012, Indonesian Students Scientific Literacy was in the $64^{\text {th }}$ rank out of the 65 countries listed. In 2015, Indonesian Students Scientific Literacy was in the $62^{\text {nd }}$ rank out of the 70 countries listed. In 2018, Indonesian Students Scientific
Literacy was in the $70^{\text {th }}$ rank out of the 78 countries listed.

One of the prominent aspects of scientific literacy is Nature of Science (NOS). Numerous studies revealed that a proper understanding of the NOS is essential for scientific literacy and that NOS can be learned best by the explicit approach (Abd-El-Khalick \& Lederman, 2000a; Donovan-White, 2006; Khishfe \& Abd-ElKhalick, 2002; Lederman 2007; McComas, 2000). Allchin (2004) stated that "basic scientific concepts provide a framework. But one must also know about science - how research is pursued, how conclusions are justified, even how scientists may sometimes error be shaped by cultural biases". Many science education documents such as the American Association for the Advancement of Science and the National Research Council emphasize an important role in 
improving students' understanding of NOS. NOS is important because it is needed to make, manage and process scientific and technological objects, inform decision making on socioscientific issues, respect the value of science as a culture of the present, NOS develop an understanding of the norms of the scientific community to realize a moral commitment that is of general value to the community and facilitating the subject matter of science learning (Hardianty, 2015).

In fact, for many science teachers, fruitful educating of NOS is demanding. Also for chemistry teacher since they should introduce NOS for grade X students while teaching nature of chemistry and scientific method as. That is the first matter for chemistry learning in senior high school. However, science teachers frequently do not really have adequate comprehension of NOS, and in any event, having such a comprehension does not ensure students' learning of NOS (Lederman, 2007). Notwithstanding an adequate comprehension of NOS, teachers additionally need to have reasonable instructive aptitudes and substance information to train NOS and they have to appreciate NOS as a learning objective (Lederman, 1999). Teacher also need to make a reasonable plan to be success in teaching NOS. Regarding to that issue, learning activity that can help teacher for teaching NOS in classroom and could foster students' NOS is needed to develop.

The phrase "nature of science" commonly alludes to the epistemology of science, science as a method of knowing, or the values/qualities and convictions inborn to the development of scientific knowledge (Lederman, 1992, 2007). Beyond these general portrayals, no agreement directly exists among scholars of science, antiquarians of science, researchers, and science teachers on a particular definition for NOS. This absence of agreement, in any case, should not be perplexing nor astonishing given the multifaceted nature and unpredictability of the logical attempt. Conceptions of NOS have changed all through the improvement of science and orderly contemplating science and are reflected in the manners the logical and science instruction networks have characterized the expression "nature of science" during the previous 100 years (e.g., AAAS, 1990, 1993; California Department of Education, 1990; Center of Unified Science Education at Ohio State University, 1974; Central Association for Science and Mathematics Teachers, 1907; Klopfer \& Watson, 1957; NSTA, 1982).

Lederman, Lederman, and Antink (2013) suggested that there are seven aspects of the NOS that are noncontroversial and accessible to K-12 students and which are also considered to be relevant to their daily lives: scientific knowledge is tentative (subject to change); empirically-based (based on and/ or derived from observations of the natural world); subjective and/or theory-laden; partly the product of human inference, imagination, and creativity (involves the invention of explanation); socially and culturally embedded; the distinction between observations and inferences, and the function of, and relationships between scientific theories and laws.

\section{METHOD}

This study followed Four-D Model (Thiagarajan, Semmel, \& Semmel, 1974) in designing the learning activity. There were four steps covered Define, Design, Develop, and Disseminate but this study just reported till Develop step.

Define step started by searched relevant literatures and conducted initial interview with chemistry teacher about teaching NOS in senior high school. The result showed 
that teaching NOS mostly was implemented by context-based learning; inquiry; and Science, Technology, and Society (STS) approaches. Also, chemistry teachers still have not introduce about NOS explicitly during chemistry learning since many difficulties. These difficulties included ways to integrated NOS with chemistry topics/ matters and used appropriate strategy.

Design step conducted by arranged of learning activity design based on result of Define step. Design included chosen learning approach for developing learning activity namely context-based (STS) that founded by Yuenyong (2006) and chemistry topic scope of eleventh grade namely Nature of Chemistry and Scientific Method (Regulation of Indonesian Ministry of Education and Culture Number 37 Year 2018).

In the Develop step, learning activity design was described in five steps regarding to the features of context-based STS. The description give guideline the activities that should conduct by students and teacher in explicating NOS. The learning activity was developed with topic a history of the Father of Modern Chemistry for grade $10^{\text {th }}$.

Data collection was carried out in two stages, namely expert judgment and questionnaire. Expert's suggestions were related to the construct accuracy of the context-based STS, the accuracy of the concept, grammar and writing. These suggestions were used to revise the learning activities. Meanwhile, the questionnaire was used to determine the feasibility of a learning activity according to the chemistry teacher view as a potential user. The closed questionnaire consists of 10 statements which represent two aspects, namely, feasibility in terms of content and feasibility in terms of language. The questionnaire consists of three alternative choices i.e. good, moderate, and less good.
Expert suggestions data was only processed qualitatively by mapping the types of suggestions and used as a basis for improving learning activities. The questionnaire data from 10 chemistry teachers were analyzed quantitatively by percentage.

\section{RESULT AND DISCUSSION}

The lesson plan of Nature of Science NOS learning activity was developed on the concept of Context-based STS learning approach which the NOS learning activities should provide not only the ways of investigation and solving problem but also a real-world problem-solving. Besides, this learning activity was organized for explicit NOS through a historical story. Regarding Yuenyong (2006), the contextbased STS learning approach consists of 5 stages included identification of social issues, identification of potential solution, need for knowledge, decision-making, and socialization and completion decision stage. The lesson plan could be provided in Table 1 .

This lesson plan is designed for $10^{\text {th }}$ graders who are taking up Natural Sciences Interest. Each class will be divided into some groups and each group will be tasking themselves in the solving of problems.

Stage 1. Identification of Social Issue/ History. In this stage, the teacher provides a history of the Father of Modern Chemistry (see Figure 1). Furthermore, the teacher asks students to identify the history in the worksheet.

Upon identifying the history, the teacher will ask some questions. In this case, the questions are divided into three parts. That is NOS reflective questions, content questions, and social questions. NOS reflective questions aim to enhance students' NOS. Meanwhile, content questions purpose to identify students' conceptual understanding. Furthermore, 


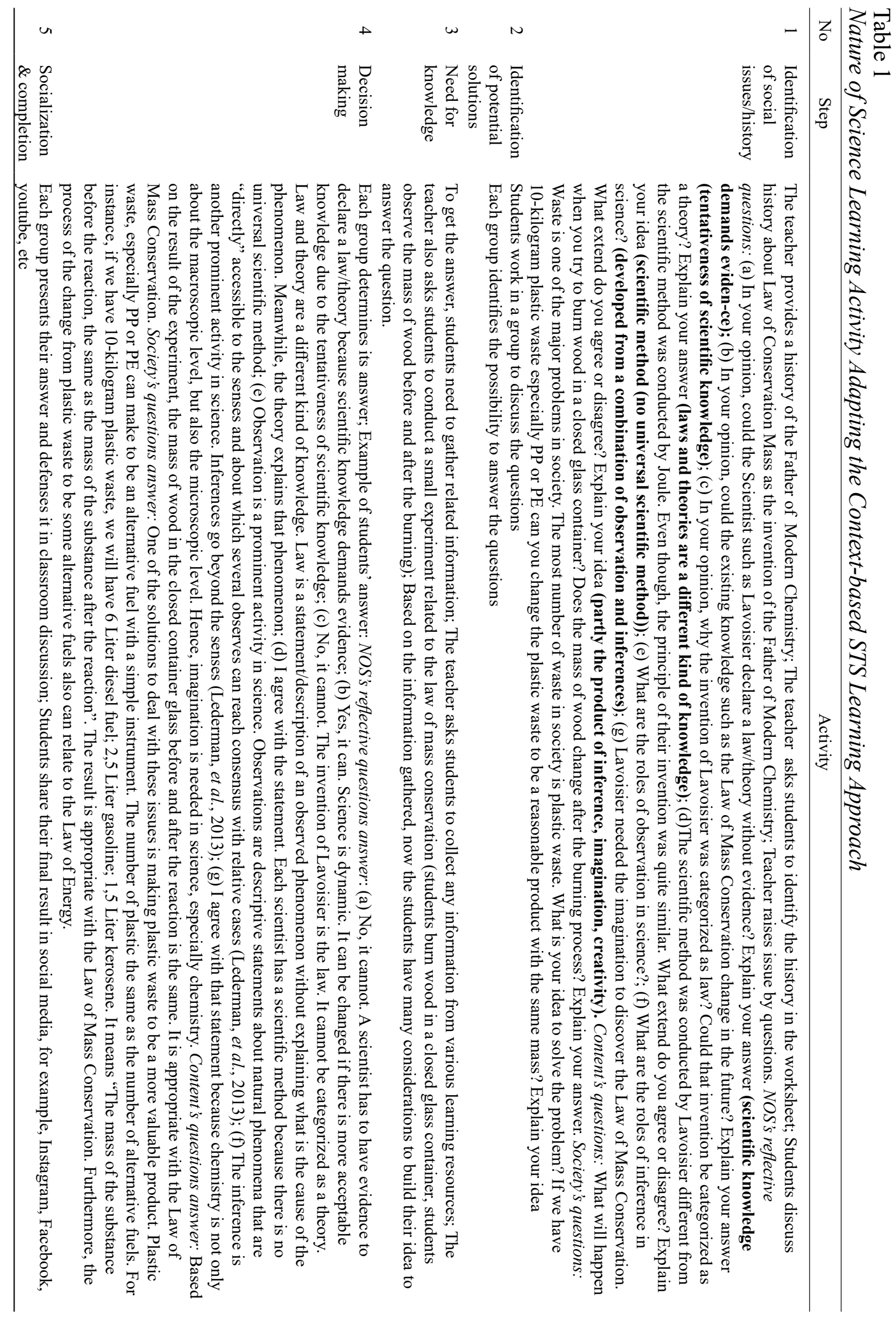


Figure 1. The History of the Father of Modern Chemistry

Father of Modern Chemistry: A Law Scholar who discovering the Law of Mlass Conservation

Antonie Laurent L avoisjer is a man who grew up from a prosperous family. He was $60 \mathrm{~m}$ on Augurs 26, 1743, he had to separase from Mary Portas, his mother because she died when he was 5 years old His father was a lawyer in the parliament of Paris, France Since he was a child, Lavoisier has had a high interest in science. However, like other people who are "lost". he chose to pursue law faculty at the age of 18 years old. The reason was his father. He wanted to be a famous lawyer like his father On the other hand. his love of the world of science kept him leaming continuously. Finally, his hard work paid off In 1799 . Lavoisier shocked the world of chemisry. Yes, the chemical world Not the world of law as he formally worked on In those years, the chemistry was still classified as "Classical Chemistry". At that time. the developing chemical theories still questioned: "water that would become a residue if it was heased continuously." At that time, scientist thought that by heating water. over time the water would tum into soil. And at the same time. Lavoisier explained the results of his research at Traite Elementaire de Chinie He tried to react to the mercury liquid with oxygen gas in a container in a closed room to produce red mercury oxide If the mercury oxide is reheated, the compound will decompose to produce the same amours of mercury liquid and oxyzen gas. By these resuls. Lavoisier's Law emerged. It was well-known as the $L$ aw of $\mathrm{Mlass}$ Conservation. "The mass of the substance before the reaction, the same as the mass of the substance after the reaction' This research instantly changed the period of 'Classical Chemisry' to a new ena: Modem Chemisty. This concept is the basis of basic chemical laws Lavoisier was named the Father of Mlodem Chemistry. In principle, the law of mass conservation is quite similar to the Law of Energy Conservation that was invented by Jarnes Prescott Joule that is "mose familiar" in which energy can only change, without being able to be created or removed. The Law of Mass Conservation proves that the mass of matter in the workd has never changed. One thing to remember in this law is that the system must be closed. If you boil, or bum, or react to an ingredient in an open container, the mass will not be the same. This law of conservation of mass can only be used for thing like that Just because youknow this theory, you can't get into a giass containes, then eat a lor. Continue to hope that the weight worit go up. The Law of Conservation of Mass discovered by Lavoisier is one of several basic chemical laws.

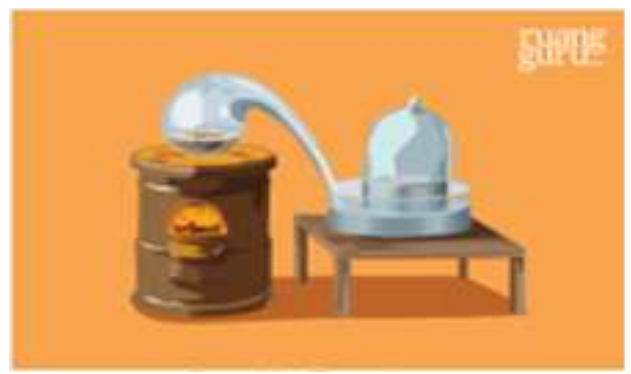

Translated and Adapted from Kresnoadi (2019)

society questions aim to know how students solve problems in their daily life. Stage 2. Identification of Potential Solution. In the second stage, the teacher facilitates the class discussion about thinking of potential solutions to answer all questions in three aspects. Each group identifies the possibility to develop their answers.

Stage 3. Need for Knowledge. In the third stage, the teacher facilitates students to gather any information from various learning resources related to the law of mass conservation. Students can collect information from books, journals, or other articles on the internet. Besides, students need to conduct a small experiment for answering the content's question. Furthermore, students need to conduct a small project to solve the problem in society. 
Stage 4. Decision-making. In the fourth stage, each group decides its answers. After that, they present their answers and defense it in the classroom. The example of students' answers is provide below.

NOS's reflective questions answer. First, No, it cannot. A scientist has to have evidence to declare a law/theory because scientific knowledge demands evidence. Second, Yes, it can. Science is dynamic. It can be changed if there is more acceptable knowledge due to the tentativeness of scientific knowledge. Third, No, it cannot. The invention of Lavoisier is the law. It cannot be categorized as a theory. Law and theory are a different kind of knowledge. Law is a statement/description of an observed phenomenon without explaining what is the cause of the phenomenon. Meanwhile, the theory explains that phenomenon. Fourth, I agree with the statement. Each scientist has a scientific method because there is no universal scientific method. Fifth, Observation is a prominent activity in science. Observations are descriptive statements about natural phenomena that are "directly" accessible to the senses and about which several observes can reach consensus with relative cases (Lederman, et al., 2013). Sixth, The inference is another prominent activity in science. Inferences go beyond the senses (Lederman, et al., 2013). Seventh, I agree with that statement because chemistry is not only about the macroscopic level, but also the microscopic level. Hence, imagination is needed in science, especially chemistry.

Content's questions answer. Based on the result of the experiment, the mass of wood in the closed container glass before and after the reaction is the same. It is appropriate with the Law of Mass Conservation.

Society's questions answer. Plastic waste, especially PP or PE can make to be an alternative fuel with a simple instrument. The number of plastic the same as the number of alternative fuels. For instance, if we have 10-kilogram plastic waste, we will have 6 Liter diesel fuel; 2,5 Liter gasoline; 1,5 Liter kerosene. It means "The mass of the substance before the reaction, the same as the mass of the substance after the reaction". The result is appropriate with the Law of Mass Conservation. Furthermore, the process of the change from plastic waste to be some alternative fuels also can relate to the Law of Energy.

Stage 5. Socialization and Completion Decision Stage. In the last stage, students have to present the result of their discussion in the classroom. Furthermore, students also have to share the result in social media, for instance, Instagram, Facebook, youtube, etc.

This learning activity could assist the teacher in teaching NOS in the classroom and could improve students' NOS through a historical story. Students who utilize the two NOS historical short stories had a significantly better understanding of the NOS concepts, compared to the students in the control group (Smith, 2010). The study of William and Rudge (2019) also revealed that the introduction of historical stories of science helped students achieved a better understanding of the role of imagination and creativity in science.

Quantitatively, for the aspect of language feasibility, all teachers (100\%) stated that the product had a good criteria. Meanwhile, for the aspect of content feasibility, 9 teachers (90\%) said it was good and 1 teacher said it was in moderate criteria. Some suggestions given by the teacher for improving the learning activity plan were providing the related links (e.g. video or the other resources), so students can study by themselves, providing the instruction of experiment to drive students, pushing 
students to conduct the other experiments to prove the content, and providing the video for apperception.

Teacher recommendations are considered to improve the learning activity plan before it is implemented in class. With the activity of adding videos, especially contextual ones, it will attract students' interest as well as curiosity. On the other hand, the selection of animation-based videos makes it possible to expand students' knowledge of how scientists think. This is important as the cultivation of NOS values which are beneficial for the development of students' thinking patterns and mental learning. Moreover, hand on activity through real experiments in the laboratory will further strengthen students' scientific understanding and skills. A good support in introducing NOS to students.

\section{CONCLUSION}

This paper shared the ideas of developing NOS learning activities regarding Yuenyong (2006) context-based STS learning approach. The 5 stages of Yuenyong (2006) context-based STS teaching approach could guide ideas of developing learning activities from history to enhance students' NOS. This learning activity will allow students to understand NOS. Furthermore, students will have the opportunity to solve a problem in society. Since this lesson plan has not been implemented yet in a school setting, for future work it could be implemented. Hence, the effect of the implementation of this NOS learning activity can be measured empirically.

\section{Acknowledgements}

I would like to thank Khon Kaen University, Thailand who has given full support so that this paper can be realized.

\section{RERERENCES}

AAAS [American Association for the Advancement of Science]. (1990). Science for all Americans. New York: Oxford University Press.

AAAS [American Association for the Advancement of Science]. (1993). Benchmarks for science literacy: A project 2061 report. New York: Oxford University Press.

Abd-El-Khalick, F. S., \& Lederman, N. G. (2000a). Improving science teachers' conceptions of the nature of science: A critical review of the literature. International Journal of Science Education, 22(7), 665-701.

Allchin, D. (2004). Error and the nature of science. American Institute of Biological Sciences.

Central Association of Science and Mathematics Teachers. (1907). A consideration of the principles that should determine the courses in biology in secondary schools. School Science and Mathematics, 7, 241-247.

Cigdemoglu, C., Arslan, H. O., \& Cam, A. (2017). Argumentation to foster preservice science teachers' knowledge, competency, and attitude on the domains of chemical literacy of acids and bases. Chemistry Education Research and Practice, 18(2), 288303. DOI:10.1039/c6rp00167j.

Donovan-White, C. (2006). Teaching the nature of science. ACASEJAEESA, 1(7), 1-24.

Hardianty, N. (2015, June). Nature of science: Bagian penting dari literasi sains. Presented at Simposium Nasional Inovasi dan Pembelajaran Sains 2015 (SNIPS 2015). Bandung, Indonesia.

Jarman, R., \& McClune, B. (2007). Developing scientific literacy: Using news media in the classroom. 
New York, NY: The McGraw-Hill Companies.

Khishfe, R., \& Abd-El-Khalick, F. (2002). Influence of explicit and reflective versus implicit inquiry-oriented instruction on sixth graders' views of nature of science. Journal of Research in Science Teaching, 39(7), 551-578.

Klopfer, L. E., \& Watson, F. G. (1957). Historical materials and high school science teaching. The Science Teacher, 24(6), 264-293.

Kresnoadi.(2019). Kimia kelas 10 mengenal Antoine Lavoisier, Bapak Kimia Modern Penemu Hukum Kekekalan Massa. Retrieved from https://blog. ruangguru.com/antoine-lavoisier.

Lederman, N. G. (1992). Students' and teachers' conceptions of the nature of science: A review of the research. Journal of Research in Science Teaching, 29(4), 331-359.

Lederman, N. G. (1999). Teachers' understanding of the nature of science: Factors that facilitate or impede the relationship. Journal of Research in Science Teaching, 36, 916-929.

Lederman, N. G. (2007). Nature of science: Past, present, and future. In S. K. Abell \& N. G. Lederman (Eds.), Handbook of Research on Science Education (pp. 831-879). London: Lawrence Erlbaum Associates.

Lederman, N. G., Lederman, J. S., \& Antink, A. (2013). Nature of science and scientific inquiry as contexts for the learning of science and achievement of scientific literacy. International Journal of Education in Mathematics, Science and Technology, 1(3), 138147.

McComas, W. F. (Ed.). (2000). The nature of science in science education rationales and strategies. The Netherlands: Kluwer Academic Publishers.

Minister of Education and Culture. (2018). Regulation of Indonesian Ministry of Education and Culture Number 37 Year 2018. Jakarta: Indonesian Ministry of Education and Culture.

NSTA [National Science Teachers Association]. (1982). Sciencetechnology-society: Science education for the 1980s. (An NSTA position statement). Washington, DC: Author.

OECD. (2015). Scientific literacy: $A$ framework for PISA 2015. Paris: OECD.

Shwartz, Y., Ben-Zvi, R., \& Hofstein, A. (2006). The use of scientific literacy taxonomy for assessing the development of chemical literacy among high-school students. Chemistry Education Research and Practice, 7(4), 203-225. DOI:10.1039/ B6RP90011A.

Smith, J. A. R. (2010). Historical short stories and the nature of science in a High School Biology Class (Graduate Theses and Dissertations). Iowa State University, Iowa.

Thiagarajan, S., Semmel, D. S, \& Semmel, M. I. (1994). Instructional development for training teachers of exceptional children. Minneapolis, Minnesota: Leadership Training Institute/Special Education, University of Minnesota.

William, C. T., \& Rudge, D. W. (2019). Effects of historical story telling on student understanding of nature of science. Science and Education, 28(9-10), 1105-1103. DOI: 10.1007/ s111191-019-00073-x.

Yuenyong, C. (2006). Teaching and learning about energy: Using STS approach (DSc thesis). Bangkok: Kasetsart University. 